\title{
Enhancement Effect of Humic Acid on Removal of Lead from Soil by Electrokinetic Process
}

\author{
Toko Iwamura, ${ }^{*}$ Yasuhiro AKemoto, ${ }^{*}$ and Shunitz TANAKA $* * *, * * * \dagger$ \\ *Graduate School of Environmental Science, Hokkaido University, Kita 10 Nishi 5, Kita, Sapporo, \\ Hokkaido 060-0810, Japan \\ **Faculty of Environmental Earth Science, Hokkaido University, Kita 10 Nishi 5, Kita, Sapporo, \\ Hokkaido 060-0810, Japan \\ ***Hokkaido Center of Environmental Science and Technology (General Incorporated Foundation), \\ Kita 24 Nishi 14, Kita, Sapporo, Hokkaido 001-0024, Japan
}

\begin{abstract}
The environmentally friendly electrokinetic process was investigated using model contaminated soil with $\mathrm{Pb}$ and humic acid. Although humic acid has a negative charge, it moved toward the cathode side by electroosmotic flow. The removal efficiency of $\mathrm{Pb}$ from model contaminated soil was $48.0 \%$ under $1 \mathrm{~V} / \mathrm{cm}$ of the potential gradient after $72 \mathrm{~h}$ of operation, while it improved to $72.6 \%$ with humic acid. These results indicated that humic acid has high potential for application in the environmentally friendly remediation of soil.
\end{abstract}

Keywords Soil treatment, electrokinetic process, lead, humic acid, pyrophyllite, electroosmotic flow

(Received December 31, 2019; Accepted February 18, 2020; Advance Publication Released Online by J-STAGE March 20, 2020)

\section{Introduction}

Contaminated soils with inorganic substances exceeding the legal standards were reported more than 1800 times in Japan in $2017 .^{1}$ If these contaminated soils containing pollutants, such as heavy metals, are left unattended, the pollutants will continue to be discharged for a long time. Therefore, on-site soil remediation is required to avoid the spread of the pollutants and secondary pollution.

The electrokinetic (EK) process is one of the on-site remediation technologies for soil, in which electromigration and electroosmotic flow (EOF) are used to transport pollutants in soil. ${ }^{2}$ The remediation of contaminated soil with heavy metals and harmful organic substances by the EK process has been investigated. ${ }^{3-7}$ Recently, the application of the EK process to soil contaminated with radioactive $\mathrm{Cs}$ has been performed. ${ }^{8-12}$ To enhance the removal efficiency of heavy metals from soil, a strong inorganic acid or artificial chelating reagent such as EDTA was used. ${ }^{13,14}$ However, the use of these substances may cause secondary pollution.

Humic acid (HA) is one of the organic substances in soil, which is produced by the degradation of dead plants chemically and biologically. HA has an interaction with various heavy metals and organic substances to solubilize these substances. ${ }^{15-18}$ The migrating behaviors of heavy metals in soil by the EK

$\dagger$ To whom correspondence should be addressed.

E-mail: shunitz@ees.hokudai.ac.jp

Y. A. present address: Industrial Research Institute, Industrial Technology Research Department, Hokkaido Research Organization, Kita 19 Nishi 11, Kita, Sapporo, Hokkaido 060-0819, Japan. process are also affected by the presence of $\mathrm{HA}$, and the applications of HA to the remediation of contaminated soil by the EK process have been investigated. ${ }^{19-22}$

In this study, the migrating behavior of HA in the EK process was investigated at first and then the enhancement effect of HA on the removal of $\mathrm{Pb}$ was demonstrated. Finally, the roles of HA for the removal of heavy metals in soil by the EK process were discussed for the development of an environmentally friendly soil remediation method.

\section{Experimental}

\section{Reagents and chemicals}

White clay (Practical Grade, Wako Pure Chemical Industries, Ltd.) was used as the model soil. This material includes pyrophyllite (one of the clay mineral) and quartz. ${ }^{12}$ In this paper, white clay was expressed as "pyrophyllite". $\mathrm{Pb}\left(\mathrm{NO}_{3}\right)_{2}$, $\mathrm{NaOH}$ and $\mathrm{HCl}$ were purchased from Wako Pure Chemical Industries, Ltd. HA was purchased from Sigma Aldrich Co. Distilled water (DW) was used for the preparation of the sample solutions.

\section{Preparation of model soil}

The model soil containing HA was prepared by the following procedure. Powdery HA was added to pyrophyllite to achieve $5 \mathrm{wt} \%$, and four times as much DW as the soil by weight was added to the mixture of HA and pyrophyllite. The mixture was horizontally shaken for $24 \mathrm{~h}$ at $170 \mathrm{rpm}$ by Multi Shaker (MMS3010 , EYELA). Then it was dried at $80^{\circ} \mathrm{C}$ in a dry oven DK-62 (Yamato Scientific Co., Ltd.) until complete dryness. The dried soil was crushed by a mortar and used as the model soil containing HA. The model contaminated soil containing lead 


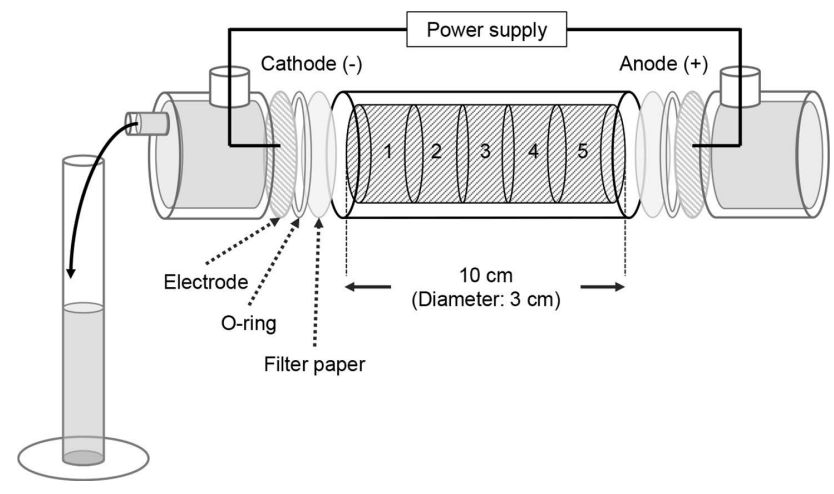

Fig. 1 Schematic diagrams of equipment for the electrokinetic (EK) process in this study.

$\left(0.3 \mathrm{mg} \mathrm{Pb} \mathrm{Pb}^{2+} / \mathrm{g}\right)$ was prepared by the following procedure. Powdery $\mathrm{Pb}\left(\mathrm{NO}_{3}\right)_{2}$ was added to pyrophyllite and $\mathrm{DW}$ was added to adjust the soil moisture $(30 \mathrm{wt} \%)$. The soil sample was mixed well and used as the model contaminated soil. The equipment for the EK process as shown in Fig. 1 is the same as that used in our previous study. ${ }^{12}$

\section{Analytical procedure}

The soil sample in the migration chamber was divided into five sections after the EK process and each soil sample was dried at $80^{\circ} \mathrm{C}$ for $12 \mathrm{~h}$. Then, $0.1 \mathrm{~mol} / \mathrm{L} \mathrm{NaOH}$ solution was added to the dried soil sample (solid:liquid ratio was 1:10), and it was mixed for $4 \mathrm{~h}$ at $1500 \mathrm{rpm}$ by a Cute Mixer (CM-1000, EYELA). The mixture was separated by centrifugation for $15 \mathrm{~min}$ at $4000 \mathrm{rpm}$ (2410, Kubota Corp.). The concentration of HA in the supernatant was estimated as the total organic carbon measured by TOC equipment (5000A, Shimadzu Corp.).

The extraction procedure of $\mathrm{Pb}$ in soil after the EK process was performed according to the following procedure. First, $1 \mathrm{~mol} / \mathrm{L} \mathrm{HCl}$ was added to the dried soil sample (solid:liquid ratio was 1:10) after the EK process. The mixture was shaken for $12 \mathrm{~h}$ at $1500 \mathrm{rpm}$ and then centrifuged for $15 \mathrm{~min}$ at $4000 \mathrm{rpm}$. The concentration of $\mathrm{Pb}$ in the supernatant was measured by atomic absorption spectrophotometer (AAS) (A-2000, Hitachi Ltd.) at $217.0 \mathrm{~nm} .{ }^{4}$ Adding DW to the dried sample after the EK process (solid:liquid ratio was 1:5) and mixing it for $1 \mathrm{~h}$ at $1500 \mathrm{rpm}, \mathrm{pH}$ of the mixture was measured using a $\mathrm{pH}$ meter (M-13, Horiba Ltd.). The solutions in anode, cathode chambers and a cylinder receiving the overflow of the EOF were used for the measurement of $\mathrm{HA}$ and $\mathrm{Pb}$. The removal efficiency of $\mathrm{Pb}$ in the sample soil was calculated by the following Eq. (1).

$$
\text { Removal efficiency }(\%)=C_{\text {before }} / C_{\text {after }} \times 100
$$

Here, $C_{\text {before }}$ and $C_{\text {after }}$ indicate the concentration of $\mathrm{Pb}$ in soil before and after the EK process at section $3(\mathrm{mg} / \mathrm{g})$.

\section{Results and Discussion}

First, the migration behavior of HA in the EK process was investigated. Pyrophyllite soil without HA was used to fill in all sections of the migration chamber except section 3 . The soil containing HA was located in section 3 and the movement of $\mathrm{HA}$ in the migration chamber was observed during the EK process. As shown in Figs. $2 a$ and $2 b$, the brown color of
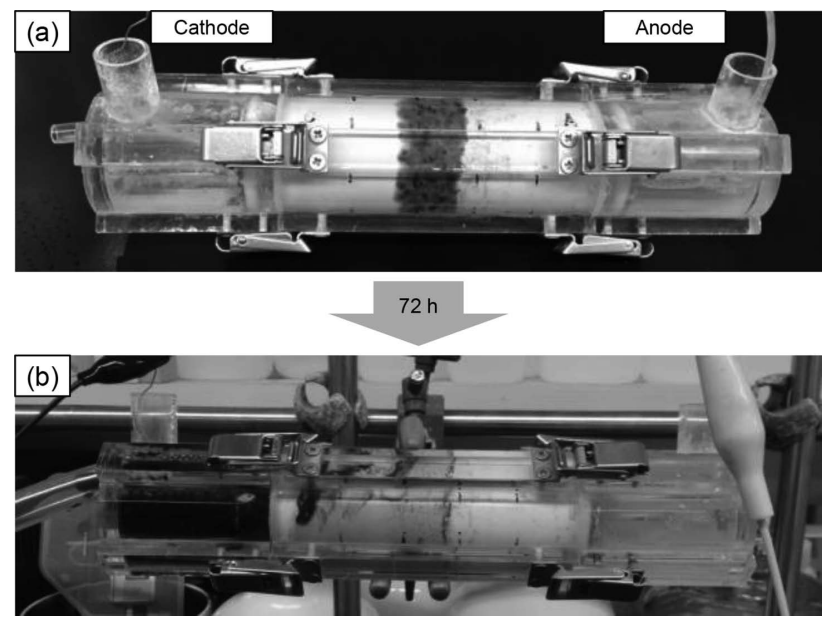

Fig. 2 (a) and (b) show the behavior of humic acid (HA) before and $72 \mathrm{~h}$ after the electrokinetic (EK) process, respectively. The potential gradient was $1 \mathrm{~V} / \mathrm{cm}$, and the migration solution was distilled water.

section 3 observed before the EK process faded after $72 \mathrm{~h}$. On the contrary, the cathode chamber changed to a brown color after the EK process. Therefore, HA seems to be transported to the cathode side by the EK process. Usually, the transportation in soil by electromigration is faster than that by EOF. Therefore, anionic species such as chloride ion and acetic ion are transported to the anode side by electromigration. ${ }^{2}$ HA has a large molecular weight and the electrophoretic mobility of HA in soil is small. Therefore, the effect of EOF, a water flow to the cathode side, was larger than that of electromigration, and consequently HA was transported to the cathode side. This result was similar to our previous research. ${ }^{20}$

If HA could be transported to the cathode side by EOF, it would be possible to supply HA added as an electrolyte in the anode chamber to the soil. Some reagents such as EDTA, organic acids and inorganic acids were added to the electrode chamber and supplied to the part contaminated with heavy metal to facilitate the removal of the metals in soil..$^{14,22}$ However, HA stayed in the anode chamber even after the $72 \mathrm{~h}$ of operation (Fig. S1, Supporting Information). It was impossible to have $\mathrm{HA}$ in the anode chamber penetrated into the migration chamber because EOF is generated only in solid media such as clay minerals but not in water. These results showed that HA should be located in soil of the anode side from pollutant to enhance the removal efficiency of pollutants in soil by using the complexing and solubilizing abilities.

To investigate the migration behavior of $\mathrm{Pb}$ by the EK process, the model contaminated soil with $\mathrm{Pb}$ was located in section 3 and other sections were filled with uncontaminated soil. Most natural soil contains organic matters, such as humic substances, therefore, the presence of HA might affect the migration behavior of $\mathrm{Pb}$ by the EK process. Figure 3 shows the distribution of $\mathrm{Pb}$ after the EK process with and without HA. $\mathrm{Pb}$ in section 3 was partially transported to section 2 of the cathode side by electromigration and EOF under the condition without $\mathrm{HA}$. However, $\mathrm{Pb}$ was not found in section 1 and the cathode chamber, and the removal efficiency of $\mathrm{Pb}$ was $48.0 \%$. Since the soil $\mathrm{pH}$ of section 1 increased to around 6 because of the generation of hydroxide by the electrolysis of water at the cathode, $\mathrm{Pb}$ began to precipitate in the hydroxide form around the interface between section 1 and 2 . Therefore, $\mathrm{Pb}$ could not reach section 1 . To investigate the effect of $\mathrm{HA}$ on the migration 

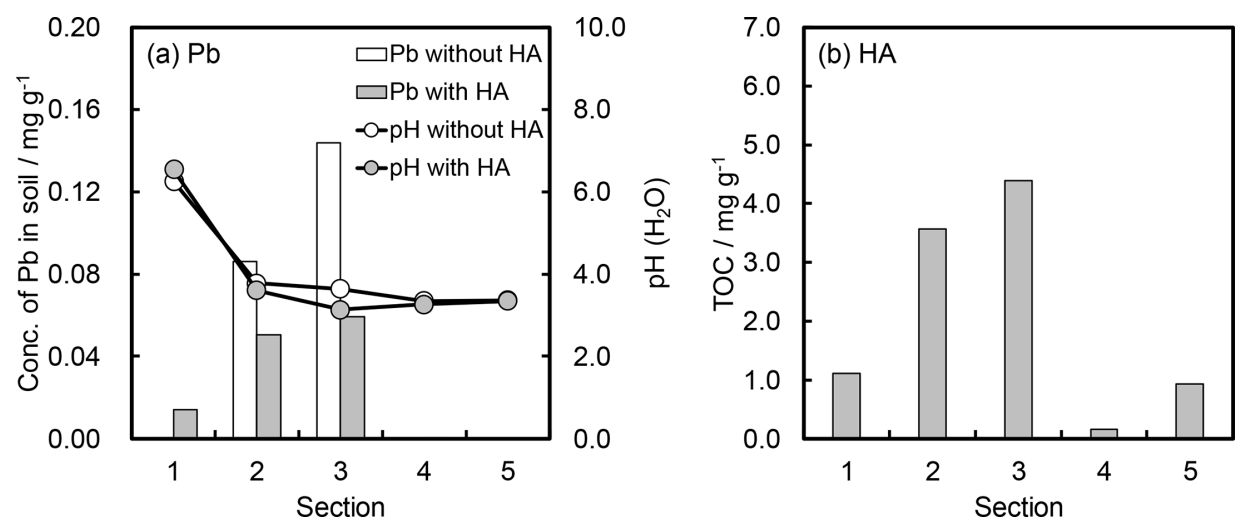

Fig. 3 Distribution of (a) $\mathrm{Pb}, \mathrm{pH}$ and (b) humic acid (HA) in soil $72 \mathrm{~h}$ after the electrokinetic (EK) process. The potential gradient was $1 \mathrm{~V} / \mathrm{cm}$, and the migration solution was distilled water.

behavior of $\mathrm{Pb}$ by the EK process, powdery HA was mixed with the dried model soil contaminated with $\mathrm{Pb}$ and the mixed contaminated soil was located in section 3. It was found that $72.6 \%$ of $\mathrm{Pb}$ in section 3 was transported to the cathode side with HA (the removal efficiency was $72.6 \%$ ). Usually, $\mathrm{Pb}$ is transported to the cathode side by electromigration as ionexchanging on the surface of clay mineral. However, when HA exists, $\mathrm{Pb}$ interacts more with $\mathrm{HA}$ than with the clay mineral. ${ }^{23}$ Since HA is transported to the cathode side by EOF, as a result, the interaction between $\mathrm{Pb}$ and the clay mineral became weak and the removal efficiency of $\mathrm{Pb}$ was enhanced by the presence of $\mathrm{HA}$. Moreover, $\mathrm{Pb}$ was not observed in section 1 without $\mathrm{HA}$ but observed in section 1 and the cathode chamber in the presence of HA after the EK process. The main interaction between $\mathrm{Pb}$ and $\mathrm{HA}$ was reported as a binding with two carboxylic groups, or with one carboxylic group and one phenolic group. ${ }^{24}$ When pyrophyllite containing $\mathrm{Pb}$ and $\mathrm{HA}$ was prepared, the $\mathrm{pH}$ of the prepared pyrophyllite was 8.8. At this $\mathrm{pH}$, the carboxylic group was almost completely deprotonated, but the phenolic group was not deprotonated. ${ }^{25}$ Therefore, it was expected that $\mathrm{Pb}$ was mainly complexing with carboxylic groups on HA (Eq. (2)).

$$
\mathrm{R}_{\mathrm{HA}^{-}}\left(\mathrm{COO}^{-}\right)_{2}+\mathrm{Pb}^{2+} \longrightarrow \mathrm{R}_{\mathrm{HA}^{-}}(\mathrm{COO})_{2} \mathrm{~Pb}
$$

These results indicated that when HA is used as an additive to enhance the removal efficiency of soil contaminated with heavy metals, HA should be added to the contaminated place directly, and not be introduced from the electrolyte chamber.

\section{Conclusions}

The environmentally friendly remediation process for $\mathrm{Pb}$ was investigated by combining the EK process with HA. The effect of EOF on the movement of HA was stronger than that of electromigration, and HA was transported to the cathode side. However, in the case that HA was put in the anode chamber, HA could not easily penetrate into the soil chamber. When the EK process was applied to the model soil contaminated with $\mathrm{Pb}$, the removal efficiency of $\mathrm{Pb}$ was $48.0 \%$ without $\mathrm{HA}$. The removal efficiency of $\mathrm{Pb}$ was enhanced to $72.6 \%$ by the addition of HA. The presence of HA might weaken the interaction between $\mathrm{Pb}$ ions and clay mineral to facilitate the movement in soil, and consequently $\mathrm{HA}$ enhanced removal efficiency of $\mathrm{Pb}$.

The basic investigation on the migration behavior of $\mathrm{Pb}$ and
HA in soil by the EK process in this study will contribute to the development of environmentally friendly soil remediation. Especially, this study revealed newly how HA was transferred as interacting with heavy metals and how the migration behavior of heavy metals was affected by HA under the electric field. Since HA is widely distributed in soil and aqueous environments and affects the behavior of pollutants and nutrition in those environments, our findings that $\mathrm{Pb}$ was transported with $\mathrm{HA}$ to the cathode side in the EK process and the efficiency was enhanced by the presence of HA will also contribute to elucidate material circulation in clay soil.

\section{Supporting Information}

The behavior of HA before and $72 \mathrm{~h}$ after the EK process when HA was put in the anode chamber as electrolyte are shown in Fig. S1. This material is available free of charge on the Web at http://www.jsac.or.jp/analsci/.

\section{References}

1. Ministry of the Environment, Japan, "Report on Soil Contamination Surveys and Countermeasures", 2019, http:// www.env.go.jp/press/files/jp/111308.pdf (in Japanese).

2. Y. B. Acar and A. N. Alshawabkeh, Environ. Sci. Technol., 1993, 27, 2638.

3. A. Sawada, K. Mori, S. Tanaka, M. Fukushima, and K. Tatsumi, Waste Manag., 2004, 24, 483.

4. R. S. Putra, Y. Ohkawa, and S. Tanaka, Sep. Purif. Technol., 2013, 102, 34.

5. T. Suzuki, M. Niinae, T. Koga, T. Akita, M. Ohta, and T. Choso, Colloids Surf., A, 2014, 440, 145.

6. E. Bocos, C. Fernandez-Costas, M. Pazos, and M. A. Sanroman, Chemosphere, 2015, 125, 168.

7. G. C. C. Yang, Sci. Total Environ., 2019, 659, 963.

8. Y. Akemoto, C. Kitagawa, R. Miyamura, M. Kan, and S. Tanaka, The 13th International Symposium on Electrokinetic Remediation (EREM2014), ed. J. M. Rodríguez-Maroto, 2014, Málaga, Spain, 134.

9. G.-N. Kim, S.-S. Kim, U.-R. Park, and J.-K. Moon, Electrochim. Acta, 2015, 181, 233.

10. M. Igawa, K. Ishiyama, and B. Nanzai, Bull. Soc. Sea Water Sci. Japan, 2018, 72, 88 (in Japanese).

11. M. Kabir, Y. Hatakeyama, and S. Nakajima, Nat. Environ 
Pollut. Technol., 2018, 17, 237.

12. Y. Akemoto, M. Kan, and S. Tanaka, J. Chem. Eng. Japan, 2019, 52, 662 .

13. A. T. Yeung, C. Hsu, and R. M. Menon, J. Geotech. Eng., 1996, $122,666$.

14. K.-J. Kim, D.-H. Kim, J.-C. Yoo, and K. Baek, Sep. Purif. Technol., 2011, 79, 164.

15. H. Kerndorff and M. Schnitzer, Geochim. Cosmochim. Acta, 1980, 44, 1701.

16. M. Taga, S. Tanaka, and M. Fukushima, Anal. Sci., 1989, 5, 597.

17. S. Tanaka, K. Oba, M. Fukushima, K. Nakayasu, and K. Hasebe, Anal. Chim. Acta, 1997, 337, 351.

18. R. Kodama, K. Sazawa, T. Miyamoto, Q. Zhu, M. Igarashi, K. Oda, H. Kuramitz, and M. Fukushima, Chemosphere,
2018, 204, 63.

19. K. R. Reddy and S. Chinthamreddy, Waste Manag., 1999, 19, 269.

20. A. Sawada, S. Tanaka, M. Fukushima, and K. Tatsumi, J. Hazard. Mater., 2003, B96, 145.

21. A. Giannis, E. Gidarakos, and A. Skouta, Desalination, 2007, 211, 249.

22. F. Rozas and M. Castellote, Electrochim. Acta, 2012, 86, 102.

23. I. Heidmann, I. Christl, and R. Kretzschmar, Geochim. Cosmochim. Acta, 2005, 69, 1675.

24. W. L. Yan and R. Bai, Water Res., 2005, 39, 688.

25. D. E. Wilson and P. Kinney, Limnol. Oceanogr., 1977, 22, 281. 